\title{
Analyticity and the Deviant Logician: Williamson's Argument from Disagreement
}

\author{
Brian Flanagan
}

Received: 22 March 2012 / Accepted: 4 July 2012 / Published online: 22 September 2012

(C) Springer Science+Business Media B.V. 2012

\begin{abstract}
One way to discredit the suggestion that a statement is true just in virtue of its meaning is to observe that its truth is the subject of genuine disagreement. By appealing to the case of the unorthodox philosopher, Timothy Williamson has recast this response as an argument foreclosing any appeal to analyticity. Reconciling Quine's epistemological holism with his treatment of the 'deviant logician', I show that we may discharge the demands of charitable interpretation even while attributing trivial semantic error to Williamson's philosophers. Williamson's effort to generalize the argument from disagreement therefore fails.
\end{abstract}

Keywords Analyticity· Disagreement · Epistemological holism · Williamson, Timothy · Quine, Willard Van Orman

One way to discredit the suggestion that a statement is analytic, that is, is true just in virtue of its meaning, is to observe that it has been the subject of disagreement. The argument from disagreement is an elaboration of the paradox of analysis - the ancient problem of how a statement can be both analytic and informative-and is a central feature of contemporary debate in a variety of fields, notably metaethics, ${ }^{1}$ legal philosophy, ${ }^{2}$ and philosophy of language. ${ }^{3}$

In his 2007 book, The Philosophy of Philosophy, and in contributions to a series of subsequent symposia, Timothy Williamson recasts the argument from disagreement as an argument foreclosing any appeal to analyticity. ${ }^{4}$ To succeed, Williamson must

\footnotetext{
${ }^{1}$ See e.g., Frank Jackson (1998, pp. 139-62); (Schroeter and Schroeter 2009). of the nature of law; e.g., Brian Leiter (2009); Scott Shapiro (2011 pp. 234-330). that have begun to receive sustained empirical attention; see e.g., (Machery et al. 2004); (Systema and Livengood 2011); Jonathan Ichikawa et al. (forthcoming).

${ }^{4}$ The argument is prefigured in Williamson (2006).

B. Flanagan $(\bowtie)$

Department of Law, National University of Ireland, Maynooth, Co Kildare, Ireland e-mail: brian.flanagan@nuim.ie

B. Flanagan

NYU School of Law, New York, USA
}

${ }^{2}$ Ronald Dworkin's argument from legal disagreement remains the major objection to 'social fact' accounts

${ }^{3}$ Saul Kripke's famous Gödel and Jonah scenarios are the only instances of the argument from disagreement 
resist the suggestion that disagreement concerning the truth of supposedly analytic statements is trivial, the product of mere semantic or deductive error. He does so by appealing to charity in the interpretation of possible repudiations of such statements. Williamson argues that disagreements prompted by deviant philosophers rest on more than mere trivial error. This does not exclude the possibility, however, that insofar as such disagreements concern the truth of the repudiated statements, they do indeed rest on such mistakes. The suggestion that any disagreement over the truth of the supposed analyticities is trivial remains unanswered. The effort to dismiss the existence of analytic statements by demonstrating the ever present possibility of (nontrivial) disagreement fails.

\section{The Argument Recast}

To establish that the truth of any statement is subject to disagreement, Williamson tries to show that certain statements traditionally classified as paradigmatically analytic are, or could be, rejected as false. ${ }^{5}$ Ostensibly, one such statement is P1, an elucidation of the concept of negation:

(P1) There are no true contradictions. ${ }^{6}$

Though P1 is traditionally classified as analytic, it is prominently repudiated by Graham Priest, who has asserted P2:

(P2) There are true contradictions, strictly so called. ${ }^{7}$

Given disagreement over supposedly paradigmatic analyticities such as P1, it seems that the truth of any statement is subject to disagreement, which suggests that no statement can true just in virtue of its meaning. Some have responded that Williamson's examples of the repudiation of supposed analyticities exhibit trivial semantic or deductive error. ${ }^{8}$ This response, Williamson believes, fails to do justice to the technical expertise of the deviant philosopher. I will suggest, to the contrary, that Quine has shown how we may acknowledge the expertise of the deviant philosopher, even while attributing her repudiation of the truth of the relevant statement to trivial error.

\section{A Trivially Mistaken Philosopher?}

Williamson questions the plausibility of characterizing the deviant philosopher as merely in need of semantic or deductive correction. While the resisted characterization might indeed apply to some of Williamson's notional deviants, ${ }^{9}$ to others, it does not:

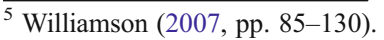

${ }^{6}$ Id 126.

${ }^{7}$ E.g., Graham Priest (1993).

${ }^{8}$ See Adrian Moore (2009, pp. 124-25); Severin Schroeder (2009, pp. 83, 85-89); Hans-Johann Glock, 'From Armchair to Reality' (2010, pp. 343-44); Paul Boghossian (2010, pp. 494-95). Indeed, in his earlier work on vagueness, Williamson was himself described as so characterizing Priest's repudiation of P1: Williamson (1992, pp. 146, 147 n 4) and Achille Varsi (2004, pp. 99-100) (responding).

${ }^{9}$ See Schroeder id 85-89 (analyzing Williamson's hypothetical repudiation of 'Every vixen is a vixen').
} 
If one had no idea who Graham Priest was and overheard him in a pub saying 'There are true contradictions', one might think at first that he was only saying that because he misunderstood the long word 'contradiction'. Once one starts talking to him, that hypothesis feels rather less attractive. ${ }^{10}$

Here is a case where the repudiation of the supposed analyticity is accompanied by an elaborate justification, one exhibiting serious philosophical reflection, ripe for academic scrutiny and debate. Pub-goers would initially report that this man Priest had misused the terms of his assertion, 'There are true contradictions, strictly so called' (P2). Having listened to Priest's argument, they would plausibly revisit their assessment: no longer would Priest seem merely in need of consulting the pub dictionary. Nevertheless, the unattractiveness of the hypothesis that Priest is asserting P2 only because he misunderstood the word 'contradiction' does not settle whether his assertion discloses a trivial error. To conclude that, charitably interpreted, Priest expresses non-trivial disagreement with the truth of P1, we must avoid Quine's famous verdict on the deviant logician, that when he tries to deny the doctrine he merely changes the subject. ${ }^{11}$

As later passages of his Philosophy of Logic make clear, Quine treats the deviant logician as raising a serious question; that of whether the explanatory return of replacing the established conceptual scheme outweighs the cost. ${ }^{12}$ By correcting the deviant logician's claim to express the literal truth while reviewing the explanatory value of the inherited scheme in light of his arguments, Quine shows how a philosopher can be charitably interpreted even while being attributed a trivial semantic error. The deviant's philosophical expertise is acknowledged by the substitution of a verdict of misuse of language with one of linguistic idiosyncrasy motivated by her advocacy of the relative explanatory weakness of the conceptual apparatus elucidated by the repudiated statement. By taking the deviant as a serious critic of that apparatus, Quine discharges the demands of charitable interpretation, thereby contradicting the suggestion that a philosopher's repudiation of the truth of a statement cannot be attributed to mere semantic error.

The relative plausibility of philosophers' conflicting appeals to the meaning of, say, 'contradiction', cannot be settled by reference to the general linguistic competence of philosophers relative to other language users. ${ }^{13}$ Faced with such conflicting

\footnotetext{
${ }^{10}$ Williamson (2009, p. 134). Similarly, Williamson (2010, p. 499) 'Once Simon has explained his view, it is much less plausible that his unwillingness to infer [the statement 'Booth shot Lincoln'] from [the statement 'Booth saw the balding Lincoln and shot him.'] manifests linguistic incompetence. It looks much more like a case of theoretical disagreement.'; Williamson (2007, pp. 89-91) '[T]o stop our logical debate with Peter and Stephen in order to explain to them what the word 'every' means would be irrelevant and gratuitously patronizing.'.

${ }^{11}$ Quine (1970, p. 81).

${ }^{12}$ E.g., '[L]et us not underestimate the price of deviant logic. There is a serious loss of simplicity, especially when the new logic is not even a many-valued truth functional logic... the price is perhaps not prohibitive, but the returns had better be good.' Id 86.

${ }^{13}$ Williamson (2007, pp. 89-91) '[B]oth [deviants] have published widely in leading refereed journals of philosophy, in English. They seem like most philosophers, thoroughly competent in their native language, a bit odd in some of their views.'; Williamson (2009, pp. 134-35) 'Moore allows that Priest may count as using the words with their standard meanings "on a looser way of speaking", but the case is utterly unlike that of a language-learner whom it would be genuinely natural to describe as having only a partial understanding of the words.'
} 
appeals, ${ }^{14}$ Williamson attributes the suggestion that the deviant is semantically mistaken to philosophical dogma. ${ }^{15}$ Unfortunately, that explanation is, in principle, equally applicable to Williamson's exemplar deviants. Moreover, the reference to philosophical dogmatism suggests that philosophers' semantic intuitions may be less reliable than those of others who are not invested in the success of semantic theories or methodologies.

Elsewhere, Williamson and others argue that philosophers' thought experimentation ought to be privileged over that of the folk. ${ }^{16}$ However this may be, sanguinity that nonconformist philosophers always, 'mean what we mean' by their words seems unjustified. We have long known of the risk that bias toward favoured theories may affect our general processes of belief formation. ${ }^{17}$ Prima facie, that risk seems likely to be more severe in the case of beliefs formed from a priori seemings than, say, those formed from perceptions of scientific instruments. Recent work on semantic intuitions confirms the effect of philosophical bias. ${ }^{18}$ Accordingly, with respect to semantic intuitions bearing on issues of theoretical significance to him, a philosopher seems less likely than other language users to avoid semantic error. The mere fact that a philosopher is 'emphatic' that he intends to use 'with their standard English senses ${ }^{19}$ the words of a statement whose repudiation is a matter of theoretical significance to him can thus do little to undermine the plausibility of a consensus to the contrary. In the case of a deviant who repudiates a supposedly analytic statement, the existence of such a consensus may be assumed.

\section{Does Quinean Holism Imply that any Statement may be False?}

Quine's semantic correction of the deviant logician forms part of a charitable interpretation because he is treated as a serious critic of the inherited conceptual scheme. Quine's interpretation depends, therefore, on his willingness to reject a statement, not

\footnotetext{
${ }^{14}$ See the critics cited at $\mathrm{n} 8$ above.

${ }^{15}$ Williamson (2009, p. 135) 'It is philosophical dogma, not respect for English, that prevents one from seeing that Priest is as linguistically competent with the words as any other normal speaker of the language.'

${ }^{16}$ E.g., Williamson (2007, p. 191) 'We should not regard philosophical training as an illegitimate contamination of the data, any more than training natural scientists how to perform experiments properly is a contamination of their data. Although the philosophically innocent may be free of various forms of theoretical bias, just as the scientifically innocent are, that is not enough to confer special authority on innocent judgment, given its characteristic sloppiness.'; Williamson (2011, p. 226) '[Sceptics offer] no reason to rely less on trained philosophers' skill at thought experimentation than on their [acknowledged] skill at those other cognitive tasks [such as formal and informal argumentation].' Similarly, Michael Devitt (2011, p. 418) 'Just as the intuitions of paleontologists, physicists, and psychologists in their respective domains are likely to be better than those of the folk, so too the intuitions of the semanticists.')

${ }^{17}$ E.g., Dawson et al. (2002 p. 1385) 'Faced with an unpalatable hypothesis, people tend to ask, in essence, "Must I believe this?" rather than "Can I believe this?"”.

${ }^{18}$ See Edouard Machery (forthcoming) 'Theoretical commitments, which differ in different groups of linguists, may sometimes influence their [semantic] intuitions, undermining the evidential role of these intuitions.... [L]inguists in different fields respond differently to the Gödel case in ways that are a priori predictable. Sociolinguists, historical linguists, and anthropological linguists, who are likely to be sensitive to the descriptions associated with words, are more likely to have descriptivist intuitions than philosophers of language and semanticists, who are likely to be familiar with Kripke's Naming and Necessity.'

19 Williamson (2007) 89.
} 
because it is false, but because criticism reveals that the conceptual scheme it elucidates is unsatisfactory in some other way. It is controversial whether the epistemological holism expressed in 'Two Dogmas' is consistent with that distinction:

Quine's epistemological holism in 'Two Dogmas' undermines his notorious later claim about the deviant logician's predicament: 'when he tries to deny the doctrine he only changes the subject. ${ }^{20}$

It is common ground that Quine's critique of the elusiveness of a satisfactory explanation of analyticity in 'Two Dogmas' is independent of its expression of a form of epistemological holism. ${ }^{21}$ But Williamson is not alone in interpreting Quine's holism as itself contradicting the claim that some statements are true just in virtue of meaning. ${ }^{22}$ The interpretation is encouraged by some suggestive remarks in 'Two Dogmas' itself. ${ }^{23}$

The question is whether we are to take the contents of our system of knowledge to be determined solely by how we distribute truth values over statements. Granted that any revision of the system redistributes truth values over the relevant statements, the revisability of every element of the system entails that no statement can be true just in virtue of its meaning. Likewise, if every revision redistributes truth values, philosophical advocacy of a particular revision could not motivate a trivially mistaken repudiation of the truth of a relevant statement. However, an alternative interpretation is available according to which the contents of our system of knowledge are not determined solely by how we distribute truth values:

Science is a continuation of common sense... The edge of the system must be kept squared with experience; the rest, with all its elaborate myths or fictions, has as its objective the simplicity of laws. ${ }^{24}$

So formulated, Quine's holism is consistent with our practice of assessing scientific hypotheses on a different footing to the conceptual apparatus with which they are framed. Whereas we may treat, 'the conceptual scheme of science as a, tool, ultimately, for predicting future experience in the light of past experience', ${ }^{25}$ it need not be thought to respond to experience in the manner of the hypotheses it serves to frame.

Conceptual schemes, no less than hypotheses, may be revised to improve our prediction of future experience. Likewise, they may be taken as epistemologically

\footnotetext{
${ }^{20}$ Williamson id 97 (citing Quine (1970, p. 81)).

${ }^{21}$ Williamson himself rejects the critique; Williamson (2007) 50, “Two Dogmas of Empiricism” does not explain why we should regard the undefined terms of semantics as worse off than the undefined terms of other disciplines, except by dogmatic charges of unclarity. After all, semantics is now a thriving branch of empirical linguistics. It is not to be trashed without very good reason.'

22 So too do critics of Williamson's argument from disagreement; see e.g., Schroder (2009, pp. 84-85); Hans-Johann Glock (1996, p. 209-10).

${ }^{23}$ See e.g., Willard Van Orman Quine (1951, p. 40) '[Given holism] it becomes folly to seek a boundary between synthetic statements, which hold contingently on experience, and analytic statements which hold come what may.'

${ }^{24}$ Id. 42.

${ }^{25}$ Quine (1951, p. 41).
} 
equivalent to hypotheses inasmuch as each can be retained, 'come what may'. ${ }^{26}$ As Quine observed, however, standards of rationality enter into the question of which revisions are to be made. ${ }^{27}$ Whereas disconfirming experience will tend to prompt revision of a hypothesis, revision of a conceptual scheme might be thought to be prompted, not by disconfirming experience, but rather by gains in the simplicity with which hypotheses may be formulated. If the epistemic considerations guiding our revisions diverge in this way, a redistribution of truth values need not be understood to accompany every revision, in which case, in contrast to discarded hypotheses, statements elucidating discarded concepts need not characterized as false. The potential for any statement to lose its place in the system would not imply that no statement is true just in virtue of its meaning.

Quine himself seems not to anticipate a redistribution of truth values in his example of the introduction of irrational numbers, omitted from later reprints:

Imagine, for the sake of analogy, that we are given the rational numbers. We develop an algebraic theory for reasoning about them, but we find it inconveniently complex, because certain functions such as square root lack values for some arguments. Then it is discovered that the rules of our algebra can be much simplified by conceptually augmenting our ontology with some mythical entities, to be called irrational numbers. All we continue to be really interested in, first and last, are rational numbers; but we find that we can commonly get from one law about rational numbers to another much more quickly and simply by pretending that the irrational numbers are there too. ${ }^{28}$

Quine's characterization of the historical decision to extend the number system dovetails neatly with his own consideration of the merit of adopting deviant logics. ${ }^{29}$ Take the statement, 'The set of numbers is countable'. The statement partially elucidates the conceptual scheme underpinning our original algebraic theory, i.e., the rational numbers. Revising that scheme by introducing a further, uncountable set of numbers simplifies mathematics, and, ultimately, improves our tools of prediction. Yet it would be odd to say that recognition of the explanatory gains contingent on the extension of the number system falsified the statement, 'The set of numbers is countable'. Certainly, that would be contrary to Quine's own description of the development. Understandings introduced by simply pretending that something is the case, bench, rather than falsify, the understandings that they displace. In contrast, revision of a scientific hypothesis or observation invariably occurs on foot of its apparent falsification; a disparity reflected in Quine's description of the statement, 'Brutus killed Caesar', as one which, 'would be false if the world had been different in certain ways'. ${ }^{30}$

\footnotetext{
26 'Any statement can be held true come what may, if we make drastic enough adjustments elsewhere in the system.' Id 40.

27 '[T] he considerations which guide him in warping his scientific heritage to fit his continuing sensory promptings are, where rational, pragmatic.' Id 43.

${ }^{28}$ Id 41. 'I think this a fair account of the introduction of irrational numbers and other extensions of the number system.' Ibid.

${ }^{29}$ See comments cited at n. 12, above.

${ }^{30}$ Id 34 (emphasis added).
} 
The holism expressed in 'Two Dogmas' plausibly respects a common sense distinction between the grounds for revising conceptual schemes and those for revising scientific hypotheses. If revision by falsification is the preserve of the latter, Quinean holism remains consistent with the possibility of truth just in virtue of meaning. Moreover, the suggested interpretation has the advantage of consistency with Quine's discussion of the deviant logician, which, by assessing the explanatory virtue of the inherited scheme in light of the deviant's arguments, succeeds in reconciling the principle of interpretive charity with the attribution of trivial semantic error. Indeed, the suggested epistemology appears consistent with Priest's most recent characterization of his own project:

[B]y forcing philosophers to struggle to find arguments for what previously was an undisputed belief, namely the one in the Law of Non-Contradiction, dialetheism would have rendered a valuable service to philosophy even if it turned out that it is ultimately wrong. ${ }^{31}$

A suite of sophisticated arguments might convince us that we ought to abandon the Law of Non-Contradiction, but would hardly reveal that, in fact, there had been true contradictions all along. Quine would recognize Priest's explicit willingness - once all the arguments are in - to concede that we in fact ought to retain classical logic as a natural consequence of their shared holism. So would Williamson's pub-goers.

\section{Conclusion}

Drawing on the principle of interpretive charity, Williamson resists the suggestion that disagreement concerning the truth of supposedly analytic statements is trivial, the product of mere semantic or deductive error. However, true to his epistemological holism, Quine's treatment of the deviant logician offers a clear example of how the demands of charity may be consistent with the attribution of trivial semantic error. The force of the example is buttressed by the growing wariness of philosophical bias in semantic intuitions, which provides reason to discount the deviant's insistence that his use of language is indeed standard. In the result, Williamson's effort to generalize the argument from disagreement into a critique of the very possibility of analyticity fails to show that genuine disagreement is always possible.

\section{References}

Boghossian, P. (2010). Williamson on the A Priori and the Analytic. Philosophy and Phenomenological Research, 82, 488.

Dawson, E., Gilovich, T., \& Regan, D. T. (2002). Motivated reasoning and performance on the Wason selection task. Personality and Social Psychology Bulletin, 28, 1379.

Devitt, M. (2011). Experimental semantics. Philosophy and Phenomenological Research, 82, 418.

Glock, H. J. (1996). Necessity and normativity. In H. Sluga \& D. G. Stern (Eds.), The Cambridge Companion to Wittgenstein (pp. 198-225). Cambridge: Cambridge University Press.

Glock, H. J. (2010). From armchair to reality. Ratio, 23, 339.

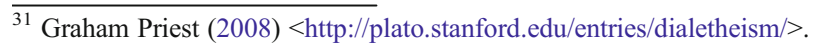


Ichikawa, J., Maitra I., Weatherson B. (forthcoming). In Defence of a Kripkean Dogma. Philosophy and Phenomenological Research.

Jackson, F. (1998). From metaphysics to ethics: A defense of conceptual analysis. Oxford: Oxford University Press.

Leiter, B. (2009). Explaining theoretical disagreement. University of Chicago Law Review, 76, 1215.

Machery, M. (forthcoming). Expertise and Intuitions about Reference. Theoria.

Machery, M., Mallon, R., Nichols, S., \& Stich, S. P. (2004). Semantics, cross-cultural style. Cognition, 92, 1.

Moore, A. W. (2009). Not to be taken at face value. Analysis, 69, 116.

Priest, G. (1993). Can Contradictions Be True?. Proceedings of the Aristotelian Society (suppl), 67, 35.

Priest, G. (2008). Dialetheism. Stanford Encyclopaedia of Philosophy

Quine, W. V. O. (1951). Two dogmas of empiricism. Philosophical Review, 60, 20.

Quine, W. V. O. (1970). Philosophy of logic. Cambridge: Harvard University Press.

Schroeder, S. (2009). Analytic truths and grammatical propositions. In H. J. Glock \& J. Hyman (Eds.), Wittgenstein and analytic philosophy (pp. 83-108). New York: Oxford University Press.

Schroeter, L., \& Schroeter, F. (2009). A third way in Metaethics. Noûs, 43, 1.

Shapiro, S. (2011). Legality. Cambridge Mass: Harvard University Press.

Systema, J., \& Livengood, J. (2011). A new perspective concerning experiments on Semantic Intuitions. Australasian Journal of Philosophy, 89, 315.

Varsi, A. (2004). Conjunction and Contradiction. In G. Priest, J.C. Beall \& B Armour-Garb (Eds.), The Law of Non-Contradiction (pp. 93-111) New York: Oxford University Press.

Williamson, T. (1992). Vagueness and Ignorance. Proceedings of the Aristotelian Society (suppl) 66, 145.

Williamson, T. (2006). Conceptual Truth. Proceedings of the Aristotelian Society (suppl), 80, 1.

Williamson, T. (2007). The Philosophy of Philosophy. Oxford: Blackwell.

Williamson, T. (2009). Replies to Kornblith, Jackson and Moore. Analysis, 69, 125.

Williamson, T. (2010). Reply to Boghossian. Philosophy and Phenomenological Research, 82, 498.

Williamson, T. (2011). Philosophical expertise and the burden of proof. Metaphilosophy, 42, 215. 